\title{
TECHNOLOGICAL DESCRIPTION FOR AUTOMATING THE CULTIVATION OF BLUEBERRIES IN BLUEBERRY PLANTATIONS ESTABLISHED ON DEPLETED PEAT MILLING FIELDS
}

\begin{abstract}
Margus ARAK, Institute of Technology, Estonian University of Life Sciences, Tartu 51006, Estonia, margus.arak@emu.ee (corresponding author)

Jüri OLT, Institute of Technology, Estonian University of Life Sciences, Tartu 51006, Estonia, jyri.olt@emu.ee

In order to increase the cost-effectiveness of blueberry (Vaccinium) cultivation in blueberry plantations, all of its technological operations should be automatized. It is reasonable to start the automation of blueberry cultivation from the technological operation of fertilising the blueberries as the main purpose of this operation is to dose a prescribed amount of fertiliser under the plant's crown. When a new blueberry plantation is established on depleted peat milling fields, then the plants are set at pre-determined steps into parallel rows. Fertilisation of the plants in the first years of growth must be performed individually, i.e. each plant is fertilised separately. This is called precision fertilisation. In order to design the technological devices for blueberry cultivation, including the fertiliser robot, it is important to know the location of plants on the field or, more precisely, their position in the row. The goal of this study is to determine the position of blueberry plants in the plantation. In order to meet the goal, measurements were performed in the blueberry plantation and the position of plants in randomly chosen row was measured. It became clear from the study that plants are not positioned regularly at equal intervals in a straight line; therefore, the fertiliser robot to be designed must include the functions of plant identification and control of fertiliser jet to ensure individual or precision fertilisation of plants.
\end{abstract}

Keywords: blueberry plantation, plant identification, position of plants, precision cultivation, robotization

\section{INTRODUCTION}

According to sources (Olt et al., 2013; Starast et al., 2002; Retamales, Hancock, 2018; Zydlik et al., 2016), the blueberry (Vaccinium) cultivation system contains the following technological operations: 1) soil preparation, 2) planting of the plants, 3) maintenance of the plantation, 4) fertilisation of plants, 5) plant protection, 6) improvement of soil properties with vaccines 7) harvesting, 8) post-harvesting processing and 9) cutting back the plants or rejuvenation pruning. These technological operations can be performed either manually or using a machine (Olt et al., 2013; Scherm et al., 2010), whereat the latter method of cultivating the blueberries is more productive and efficient than the former (Käis, Olt, 2010; Takeda et al., 2017). Blueberry plantations have been established on mineral soils, but also on depleted peat milling fields (Peatland Ecology..., 2009). Machines have been developed for performing all of the technological operations in blueberry plantations established on mineral soils.

Peat milling fields have a $\mathrm{pH}$ level and moisture regime that is suitable for blueberry cultivation (Noormets et al., 2003; Smagula et al., 2003; Arak et al., 2018); however, their ground has a low load bearing capacity and, therefore, machines with very low special pressure can be used here and, unfortunately, these have not been in the centre of attention of larger machine-building companies. A few smaller companies have produced machines and devices that can potentially be used in plantations established on peat milling fields (Olt et al., 2013).

One of the possibilities of reducing the unit cost of blueberry cultivation is by implementing machines. The use of machines in blueberry cultivation sets specific requirements to the plantation, namely the following: 1) the use of machines is possible in continuously maintenanced and pruned plantations; 2 ) in order to ensure the normal operation of servicing and harvesting machines, the ground of the plantation must be level and it should remain level during exploitation; 3) service or technical roads must be established; 40 machine harvesting requires the periodic pruning of old branches; the first rejuvenation pruning is performed from the $8^{\text {th }}$ to $10^{\text {th }}$ year, thereafter every $3-4$ years.

The efficiency of machine cultivation of berries, including blueberries, can be further increased by using the methods of precision cultivation (Chang et al., 2012) and by robotizing the performance of its technological operations. It is reasonable to start the robotization of blueberry cultivation from the fertilisation of the plantation by modelling a fertiliser robot. It must be taken into account that the availability of nutrients in the soil affects significantly the productivity of the plants (Farooque et al., 2012); greater fertilisation norms (nitrogen up to $150 \mathrm{~kg}^{-1}$ ) improve significantly the growth of the plants and improve yield (Ehret at al., 2014), especially on soils low in nutrients (Starast

Copyright (C) 2019 The Authors. Published by Vytautas Magnus University. This is an open-access article distributed under the terms of the Creative Commons Attribution License (CC-BY 4.0), which permits unrestricted use, distribution, and reproduction in any medium, provided the original author and source are credited. 
et al., 2007; Paal et al., 2011). A strong positive relation has been found between the availability of nutrients and the vegetative parameters of the blueberry plant: the plant's height and area of the leaves (Leit, 2017; Vainura, 2018).

However, fertilisation depends on the properties of a specific soil and the plant's age, which results in a specific norm for each fertiliser. From the point of view of the plant's age, it should be kept in mind that the root grows each year and this results in a larger area to be fertilised. In the first year, the fertiliser should be spread to a smaller area of about $20 \times 20 \mathrm{~cm}$ around the plant; at the age of 6-8 years, the area of plant's roots has achieved maximum dimensions (about $100 \times 100 \mathrm{~cm}$ ); this also depends on the density of plantation: if the distance between plants in a row is $150 \mathrm{~cm}$, then the area to be fertilised is $150 \times 150 \mathrm{~cm}$ ).

The following main and specific functions need to be defined to design a fertiliser robot for blueberry plants: 1) the blueberry plants in the plantation have been placed at certain intervals $(1,1.5$ and $2.0 \mathrm{~m})$ in a row and, therefore, the fertiliser robot must move in a straight line on the field along the plant row; 2) fertiliser must be spread around the plant under its crown (Hart et al., 2006); 3) blueberry plants must be fertilised 2-3 times per season by dosing 30-80 g plant ${ }^{-1}$ (less in the first years, more in the later years (Hart et al., 2006), which means that the dosing unit of the fertiliser robot must be adjustable for dosing predetermined amounts of fertiliser. It is not possible to use overall fertilisation in a blueberry plantation as this will result in the thriving of weeds and this would raise the maintenance costs unexpectedly.

If the blueberry plants would be located in one row and at fixed intervals, then the designing of the fertiliser robot would be relatively easy. However, the plant rows are usually not straight, because the plants are not located in distinct rows and the distance between them varies; therefore, the fertiliser robot must be equipped with the functions of identifying the blueberry plant and controlling the fertiliser jet. Thus, the goal of this study is to define the position of blueberry plants in plant rows in established blueberry plantations.

\section{MATERIALS AND METHODS}

Studies were carried out in June 2018 in the in Toomas Jaadla's Marjasoo farm blueberry plantation in Rannu municipality in Tartu County (Estonia) (Fig. 1).

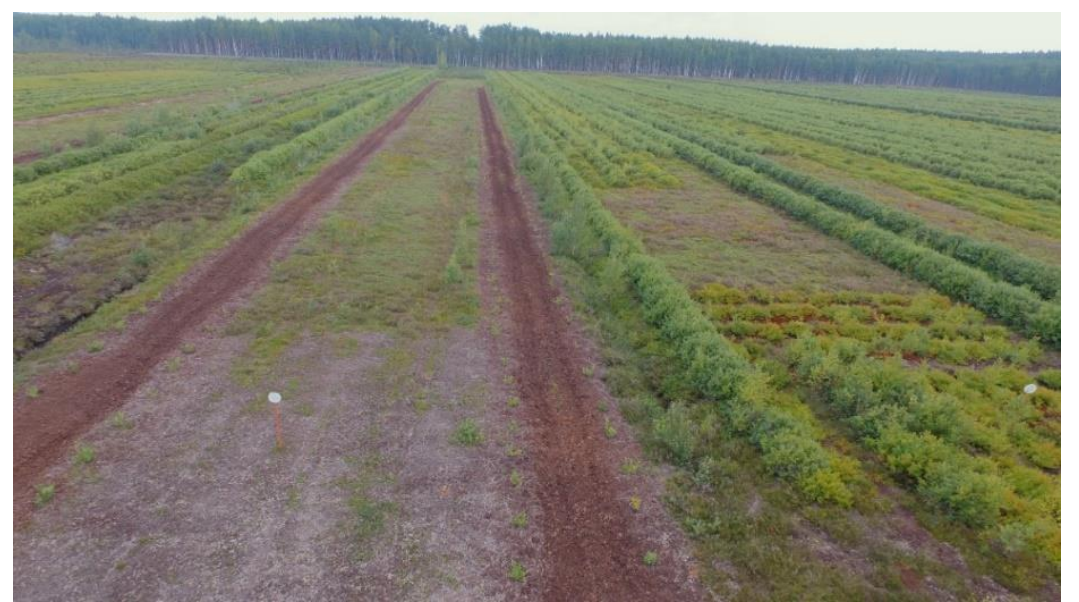

Figure 1. Top view of the Marjasoo farm's blueberry plantation (photo A. Arula, Droon Phantom Advanced)

A random plant row with plants 1 (Fig. 2) of two years of age was chosen in a young blueberry (Vaccinium angustifolium Ait.) plantation for determining the position of blueberry plants.



Figure 2. Fragment of a headland in the Marjasoo farm: 1 - plants, 2 - technical road, 3 - measuring rod (1 m) (photo A. Arula, Droon Phantom Advanced)

In order to determine the position of plants 1 (Fig. 3) in rows, rope 2 was placed $400 \mathrm{~mm}$ from the first and last plant of the row (on the side next to the technical road) and measuring tape was used to measure using the accuracy of $5 \mathrm{~mm}$. 


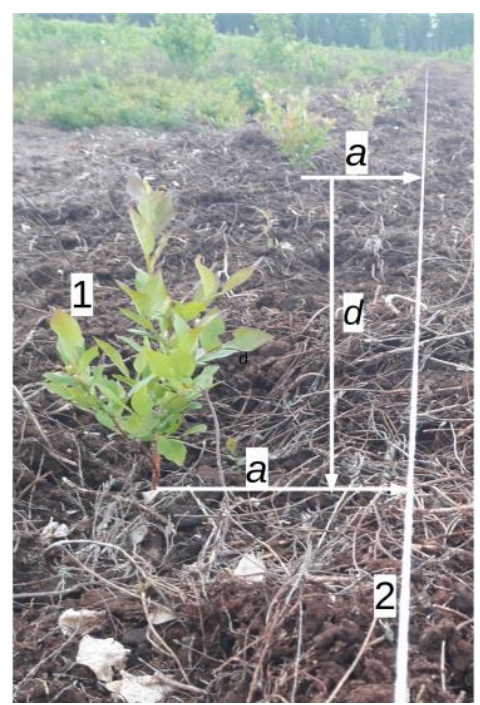

A



B

Figure 3. Scheme for determining the parameters of a blueberry plant row: parameters of the plant row (A) and geometrical parameters of the plant (B): 1 - plants, 2 - base rope, a - distance of a plant from the base (measuring) rope, $\mathrm{b}$ - length of the edge perpendicular to the measuring line of the blueberry bush's projection, $\mathrm{c}$ - length of the edge parallel to the measuring line of the blueberry bush's projection, $\mathrm{d}$ - distance between the plants, $\mathrm{h}$ - height of the plant

A crater for planting had been formed around the plant using hand tools and the plant is located in the centre of this crater (Fig. 4) with the following parameters: outer diameter of the planting crater $D_{v}=935 \mathrm{~mm}$, inner diameter of the planting crater $D_{s}=340 \mathrm{~mm}$ and height of the planting crater $h_{k}=93 \mathrm{~mm}$.

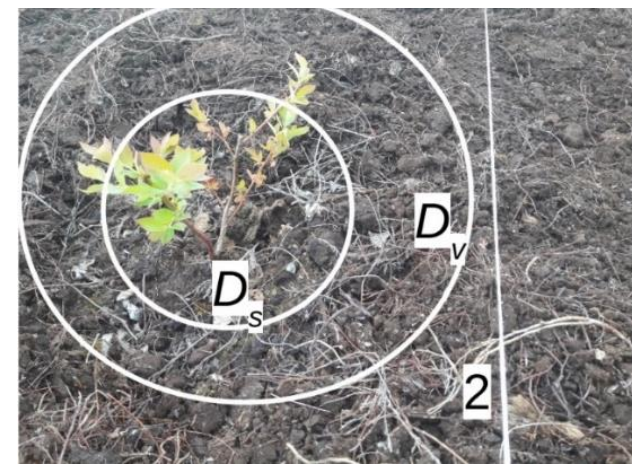

Figure 4. Parameters of the crater around the blueberry plant: $D_{v}$ is the outer diameter of the crater, $D_{s}-$ its inner diameter, $2-$ base rope.

\section{RESULTS AND DISCUSSION}

One plant row planted in 2016 in Toomas Jaadla's Marjasoo farm's blueberry plantation was chosen for measuring. The characteristic technological parameters of this row were the following: 1) total length of the row of blueberry plants is $177 \mathrm{~m}$; 2) distance between plant rows is $2.7 \mathrm{~m}$; 3) a technical road of $1.5 \mathrm{~m}$ was located between the rows; 4) the number of plants in the row is 130 , including 15 plants that have dried and 2 planting craters hold 2 plants each.

It became evident during the positioning of blueberry plants in the row (Fig. 5) that the deviation of plants from the central axis remained in the range of $-295 \mathrm{~mm}$ to $365 \mathrm{~mm}$.

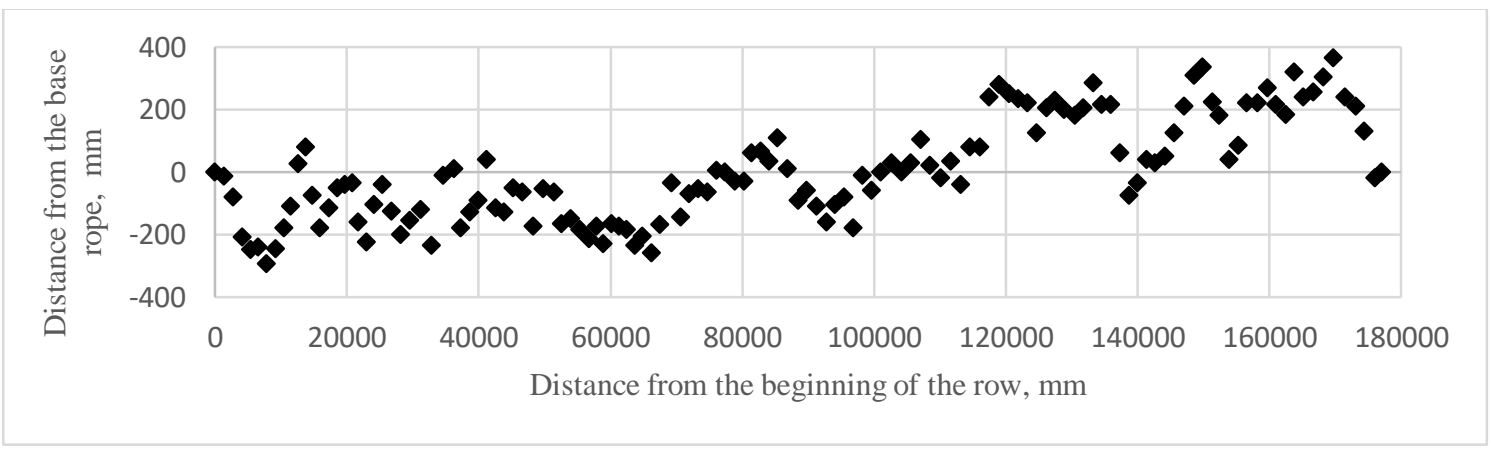

Figure 5. Position of blueberry plants in a row 
It became evident from data analysis (MS Excel) that the average distance of plants from the central axis of the plant row is relatively small (only $1.8 \mathrm{~mm}$ ); however, as the plants are located on both sides of the central axis and they have a wide range $(660 \mathrm{~mm})$, then the standard deviation is a high $\pm 162 \mathrm{~mm}$. The asymmetry multiplier (skewness) and excess (kurtosis) of the position of the plants are 0.35 and -0.86 , respectively. It can be claimed using this information that the majority of the plants are positioned to the left of the plant row and distances have concentrated away from the mean value towards the negative values. The distribution of plant positions is described in Figure 6.

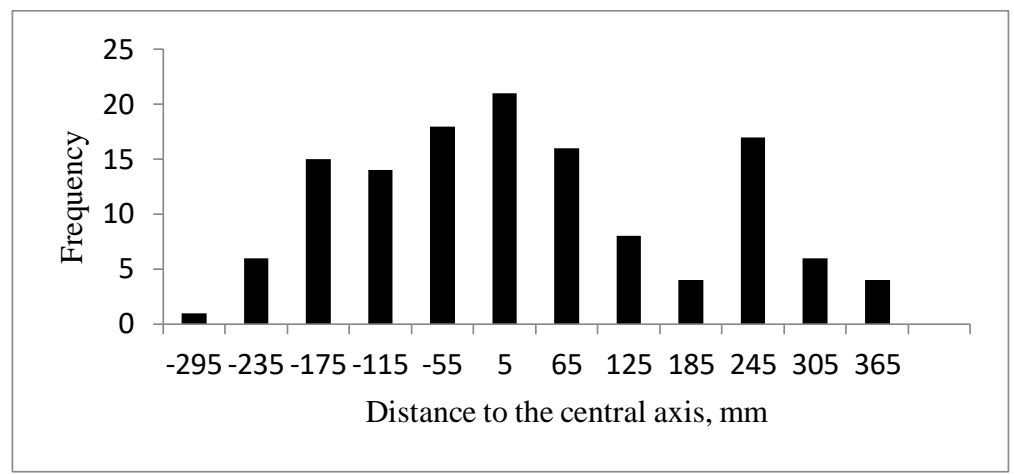

Figure 6. Histogram of the upper limits of the distance of blueberry plants to the central axis of the plant row

The mean distance of blueberry plants in the row described in Figure 2 including standard deviation, is $1372 \pm$ $166 \mathrm{~mm}$, with the minimum and maximum distance between the plants being 915 and $1800 \mathrm{~mm}$, respectively. The asymmetry multiplier (skewness) and excess (kurtosis) of the distance between the plants are -0.17 and 0.26 , respectively; this can used to claim that the majority of the distances are greater than the mean value. The distance between the plants in a plant row has been described in Figure 7.

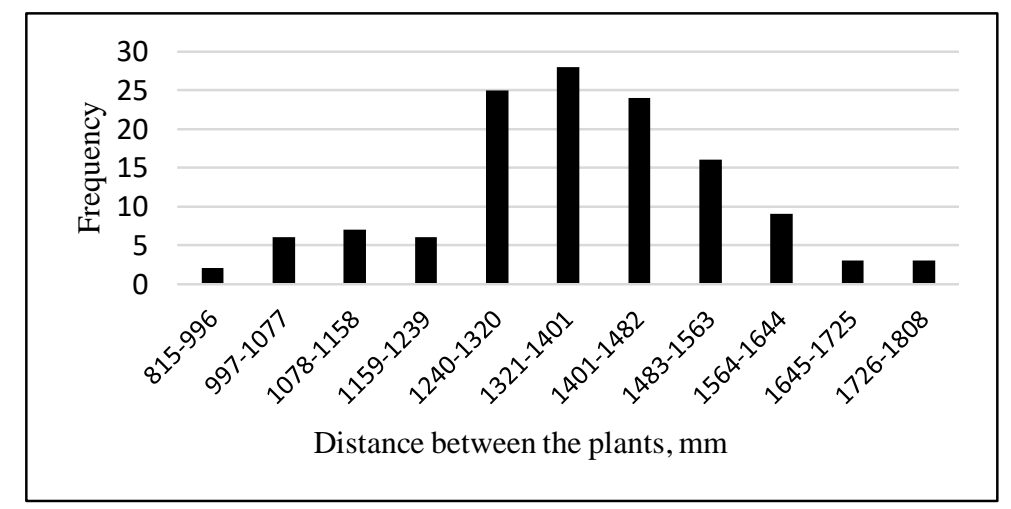

Figure 7. Histogram of the upper limits of the distance between the plants

From the point of view of modelling the fertiliser robot, it is necessary to know the dimensions of the projection of the blueberry plant's leaves. This study treats the shape of a blueberry plant as a rectangle with side's mean length, including standard deviation, being $180 \pm 84 \mathrm{~mm}$ and $189 \pm 87 \mathrm{~mm}$. The perpendicular (b) and longitudinal (c) length of the projection of leafage varies greatly: $b=50 \ldots 480 \mathrm{~mm}$ and $c=40 \ldots 440 \mathrm{~mm}$. The measurement results have been given in Table 1 and illustrated in Figures 8 and 9.

Table 1. Parameters of blueberry plant's leafage and height

\begin{tabular}{lccc}
\hline \multicolumn{1}{c}{ Parameter } & $b, \mathrm{~mm}$ & $c, \mathrm{~mm}$ & $d, \mathrm{~mm}$ \\
\hline Mean & 179.8 & 188.7 & 219.7 \\
Standard deviation & 83.7 & 86.9 & 57.9 \\
Kurtosis & 1.2 & -0.1 & 0.6 \\
Skewness & 1.1 & 0.7 & 0.3 \\
Range & 430 & 400 & 330 \\
Minimum & 50 & 40 & 60 \\
Maximum & 480 & 440 & 390 \\
\hline
\end{tabular}




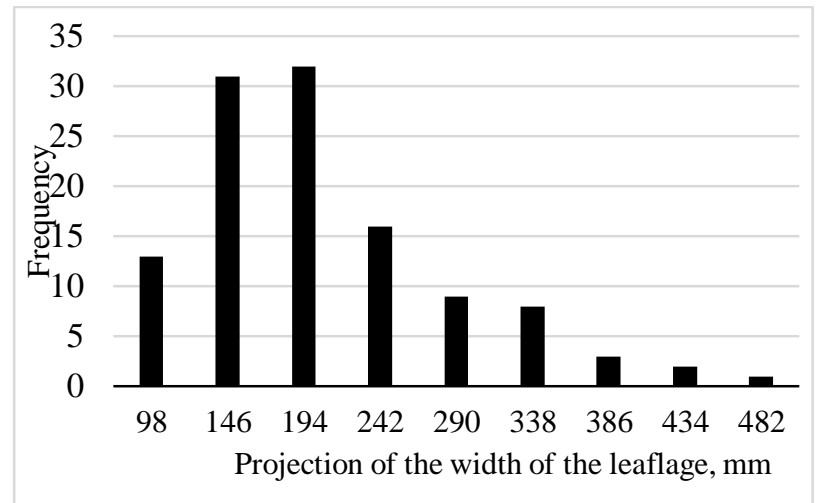

Figure 8. Histogram of the upper limits of the projection of the width of the leafage of blueberry plants

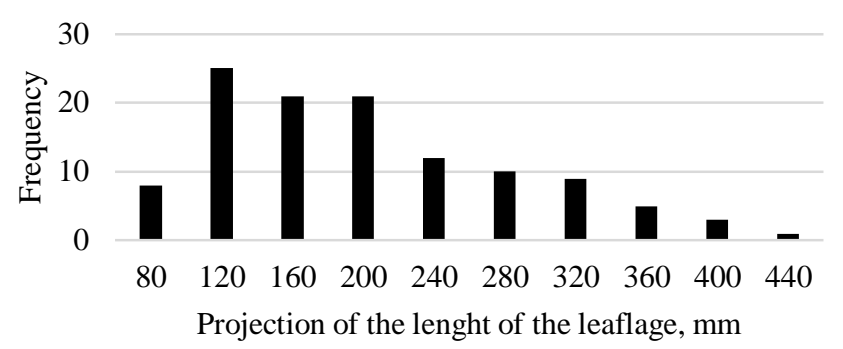

Figure 9. Histogram of the upper limits of the projection of the length of the leafage of blueberry plants

The height of the blueberry bush must be known to determine the machine's clearance. The measurement results of the heights of blueberry bushes have been illustrated in Figure 10 and statistical data has been presented Table 1.

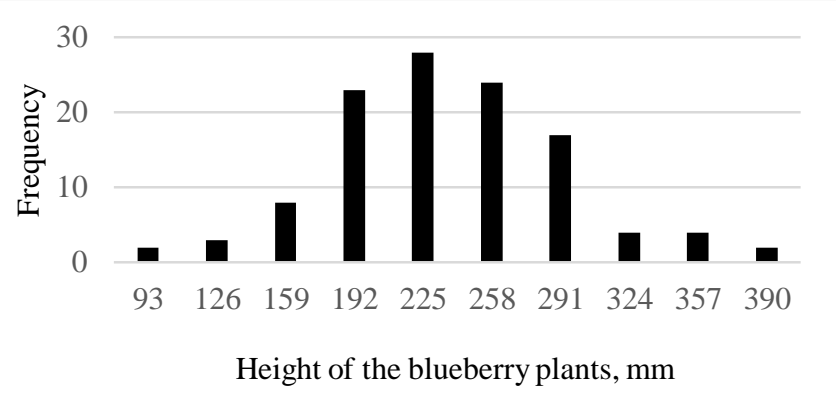

Figure 10. Histogram of the upper limits of the height of blueberry plants

Table 1 shows that the height of plants varies greatly $(330 \mathrm{~mm})$, which also gives an input for modelling the parameters of the fertiliser robot.

This study is one of the first steps in defining the technology of blueberry plantations established on depleted peat milling fields. The obtained results can be used for modelling technological machines and continuing research. Results show that manually planted plants may not be located in a straight line; the deviations from the central axis of the plant row in this study were -295 up to $365 \mathrm{~mm}$. At the same time, the distance between the plants or their interval was not homogenous and remained in the range of 915 to $1800 \mathrm{~mm}$. The values of the perpendicular and longitudinal projections of leafage vary greatly, $50 \ldots 480$ and $40 . .440 \mathrm{~mm}$, respectively. The mean height of two-year-old plants was $220 \mathrm{~mm}$, but this value also varies greatly in the range of 60 to $390 \mathrm{~mm}$.

The numerical values obtained in this study can be used to determine the overall machine-building dimensions (like the working range of the fertiliser unit, clearance of the machine) of the prototype of the fertiliser robot to be designed. The functions of an autonomous fertiliser robot must include the identification of a blueberry plant and control over the fertiliser jet in addition to the precise dosing of the fertiliser.

\section{CONCLUSION}

This study is one of the first studies to define a blueberry plantation on depleted peatland fields. The results are the basis for further research. The results shows that the manually planted plants do not lie in one narrow row, but the plants are located on both sides of the central axis in a wide range $(660 \mathrm{~mm})$. Also, the distance between plants in a row varies greatly $(915 \ldots 1800 \mathrm{~mm})$.

Consequently, the fertilizer robot to be designed must be equipped with a blueberry crop detection device and a fertilizer application control. 


\section{REFERENCES}

1. Arak M., Soots K., Starast M., Olt J. 2018. Mechanical properties of blueberry stems. Research in Agricultural Engineering, Vol. 64, pp. 202-208. https://doi.org/10.17221/90/2017-RAE

2. Chang Y. K., Zaman Q., Farooque A. A., Schumann A. W., Percival D. C. 2012. An automated yield monitoring system II for commercial wild blueberry double-head harvester. Computers and Electronics in Agriculture, Vol. 81, pp. 97-103. https://doi.org/10.1016/j.compag.2011.11.012

3. Ehret D. L., Frey B., Forge T., Helmer T., Bryla D. R., Zebarth B. J. 2014. Effects of nitrogen rate and application method on early production and fruit quality in highbush blueberry. Canadian Journal of Plant Sciences, Vol. 94, pp. $1165-1179$. https://doi.org/10.4141/cjps2013-401

4. Farooque A. A., Zaman Q. U., Schumann A. W., Madani A. Percival D. C. 2012. Delineating management zones for site specific fertilization in wild blueberry fields. Applied Engineering in Agriculture, Vol. 28, Iss. 1, pp. 57-70. https://doi.org/10.13031/2013.41286

5. Hart J., Strik B., White L., Yang W. 2006. Nutrient management for blueberries in Oregon. EM8918. Oregon State University Extension Service. Corvallis, Oregon, 16 p.

6. Käis L., Olt J. 2010. Low-bush blueberry machine cultivation technology in plantations established on milled peat fields. Kosutic S. (ed.). Actual tasks on agricultural engineering. HINUS, Vol. 38, pp. 271-279.

7. Leit I. 2017. Effect of genotype and fertilization on the chemical composition of blueberries under organic farming conditions: master thesis. Eesti Maaülikool, Tartu, Estonia, (in Estonian), 46 p.

8. Noormets M., Karp K., Paal T. 2003. Recultivation of opencast peat pits with Vaccinium culture in Estonia. Iezzi E. et al. (eds). Ecosystems and sustainable development. Southampton, Boston, Vol. IV (2), pp. 1005-1014.

9. Olt J., Arak M., Jasinskas A. 2013. Development of mechanical technology for low-bush blueberry cultivating in the plantation established on milled peat fields. Agricultural Engineering, Vol. 45, Iss. 2, pp. 120-131.

10. Paal T., Starast M., Noormets-Šanski M., Vool E., Tasa T., Karp K. 2011. Influence of liming and fertilization on lowbush blueberry in harvested peat field condition. Scientia Horticulturae, Vol. 130, Iss. 1, pp. $157-163$. https://doi.org/10.1016/j.scienta.2011.06.031

11. Peatland Ecology Research Group. 2009. Production of berries in peatlands. Guide produced under the supervision of Line Rochefort and Line Lapointe. Université Laval, Quebec, Canada, 134 p.

12. Retamales J. B., Hancock J. F. 2018. Blueberries ( $2^{\text {nd }}$ ed.). Crop Production Science in Horticulture Agriculture, book 29. CABI, 424 p. https://doi.org/10.1079/9781780647265.0000

13. Scherm H., Krewer G., Cline W. O., Harmon P., Morgan K., Takeda F. 2010. Advancing blueberry production efficiency by enabling mechanical harvest, improving fruit quality and safety, and managing emerging disease. HortScience, Vol. 45, Iss. 8, pp. 199-200.

14. Smagula J., Litten W. 2003. Can lowbush blueberry soil pH be too low? Acta Horticulturae, 626: 309-314. doi: 10.17660/ActaHortic.2003.626.43 https://doi.org/10.17660/ActaHortic.2003.626.43

15. Starast M., Karp K. Noormets M. 2002. The effect of foliar fertilisation on the growth and yield of lowbush blueberry in Estonia. Acta Horticulturae, Vol. 594, pp. 679-684. https://doi.org/10.17660/ActaHortic.2002.594.92

16. Starast M., Karp K., Vool E., Paal T., Albert T. 2007. Effect of NPK fertilization and elemental sulphur on growth and yield of lowbush blueberry. Agricultural and Food Science, Vol. 1, pp. 34-45. https://doi.org/10.2137/145960607781635859

17. Takeda F., Yang W.O., Li C., Freivalds A., Sung K., Xu R., Hu B., Williamson J., Sargent S. 2017. Applying New Technologies to Transform Blueberry Harvesting. Agronomy, Vol. 7, Iss. 33. https://doi.org/10.3390/agronomy7020033

18. Vainura K. 2018. The influence of Monterra Malt fertilizers on the productivity and fruit chemical composition of blueberry's selections (Vaccinium): master thesis, Eesti Maaülikool, Tartu, Estonia, 63 p. (in Estonian).

19. Zydlik Z., Pacholak E., Rutkowski K., Styła K. 2016. The influence of a mycorrhizal vaccine on a biochemical properties of soil in the plantation of blueberry. Zemdirbyste-Agriculture, Vol. 103, Iss. 1, pp. 61-66 https://doi.org/10.13080/z-a.2016.103.008 